\title{
Effects of Sperm Pretreatment on Efficiency of ICSI-Mediated Gene Transfer in Pigs
}

\author{
Mayuko KUROME1), Hitoshi SAITO' ${ }^{1)}$, Ryo TOMII'), Satoshi UENO'), \\ Katsumi HIRUMA ${ }^{1)}$ and Hiroshi NAGASHIMA ${ }^{1)}$
}

1) Laboratory of Developmental Engineering, Department of Life Science, School of Agriculture, Meiji University, Kawasaki 214-8571, Japan

\begin{abstract}
Intracytoplasmic sperm injection (ICSI)-mediated gene transfer has recently been shown to be an effective technique for producing transgenic pigs; however, the types of sperm pretreatment having the most beneficial effects on post-ICSI embryogenesis or transgenic efficiency have not been clarified. In the present study, we performed ICSI-mediated gene transfer using pig sperm subjected to various pretreatments and determined the developmental potential of sperm-injected oocytes and introduction efficiency of exogenous DNA. Embryos were then transferred to recipient pigs to confirm gene transfer efficiency during the fetal period. When ICSI was performed using unfrozen sperm heads with tails removed by piezo-pulse, the rates of blastocyst formation $(14.2 \%, 17 / 120)$ and transgene (EGFP) expression $(11.8 \%, 2 / 17)$ were both low. When unfrozen sperm heads were used that were removed by sonication, EGFP expression efficiency $(11 / 21,52.4 \%)$ improved significantly $(\mathrm{P}<0.05)$. Pretreatment of unfrozen sperm with a surfactant or acrosomal reaction did not further improve the rates of blastocyst formation and EGFP expression. However, use of the heads of sperm frozen-thawed with or without a cryoprotective agent resulted in rates of blastocyst formation and EGFP expression that tended to be generally high $(23.0 \%, 14 / 61-33.8 \%, 26 / 77$ and $42.9 \%, 6 / 14-66.7 \%$, 10/15). A total of 219 in vitro matured oocytes were fertilized by ICSI-mediated gene transfer using the heads of frozen-thawed sperm and then transferred into two recipient pigs. Seven fetuses were obtained, and EGFP expression and integration of the transgene (10-30 copies) were confirmed in two of the seven fetuses. Use of unfrozen sperm thus confers no advantages on ICSI-mediated gene transfer, and although further investigations are needed, frozen-thawed sperm heads appear to be useful in ICSI-mediated gene transfer.

Key words: Enhanced green fluorescent protein (EGFP), Intracytoplasmic sperm injection (ICSI)mediated gene transfer, In vitro matured oocytes, Sperm, Transgenic pig
\end{abstract}

(J. Reprod. Dev. 53: 1217-1226, 2007)

I $\mathrm{n}$ recent years, transgenic pigs have been used in a wide variety of applications, including xenotransplantation research [1-3], animal models for human diseases $[4,5]$, and production of highvalue farm animals $[6,7]$. Transgenic pigs have previously been produced by injecting a gene into the pronucleus of fertilized eggs, but new tech-

Accepted for publication: August 10, 2007

Published online: October 15, 2007

Correspondence: H. Nagashima (e-mail: hnagas@isc.meiji.ac.jp) niques to replace pronucleus injection, such as somatic cell nucleus transfer [8-11] and spermmediated gene transfer [12-14], have since been developed to further improve production efficiency.

Intracytoplasmic sperm injection (ICSI)-mediated gene transfer was first reported by Perry et al. in 1999 [15]. Using this technique, foreign genes can be introduced into oocytes by microinjecting sperm coincubated with DNA. To date, ICSI-medi- 
ated gene transfer has been used to produce transgenic mice [15-17], rats [18] and pigs [13]. However, the production efficiency of transgenic pigs by ICSI-mediated gene transfer is low, and the likelihood of producing transgenic fetuses and live piglets is less than $1 \%$ [13].

Efficient ICSI-mediated gene transfer requires use of sperm with plasma membranes damaged by freezing and thawing or by a surfactant [15]. Damage to the sperm plasma membrane causes DNA to associate with submembrane structures, and this plays an important role in the transfer of DNA into oocytes [15].

However, sperm pretreatments that markedly disrupt the plasma membrane can damage the sperm nucleus and lower embryogenesis following ICSI. If a damaged sperm head plasma membrane is a requirement for the sperm to function as an exogenous DNA vector in ICSI-mediated gene transfer, identifying the types of membrane damage that do not negatively affect embryogenesis following ICSI is important for establishment of effective methods for producing transgenic pigs. However, the pretreatments most suitable for damaging the sperm plasma membrane prior to ICSImediated gene transfer have not been clarified. We therefore conducted the present study to gather basic data on efficient production of transgenic pigs by ICSI-mediated gene transfer using in vitro matured (IVM) oocytes.

In the present study, ICSI-mediated gene transfer was first performed using sperm subjected to various pretreatments in order to determine their effects on the introduction efficiency of exogenous DNA and embryogenesis of IVM oocytes. Embryos subjected to ICSI-mediated gene transfer were then transferred to recipient pigs to assess the efficiency of gene transfer during the fetal period.

\section{Materials and Methods}

\section{Animal care}

All animal experiments in this study were approved by the Institutional Animal Care and Use Committee of Meiji University (IACUC-02-002).

\section{Chemicals}

All chemicals were purchased from the SigmaAldrich Chemical (St. Louis, MO, USA), unless otherwise indicated.
In vitro maturation of oocytes

Ovaries were collected at a local abattoir and transported to the laboratory in Dulbecco's phosphate buffered saline (D-PBS) containing $75 \mu \mathrm{g} / \mathrm{ml}$ potassium penicillin $\mathrm{G}, 50 \mu \mathrm{g} / \mathrm{ml}$ streptomycin sulfate and $0.1 \%(\mathrm{w} / \mathrm{v})$ polyvinylalcohol (PVA). Cumulus-oocyte complexes (COCs) were collected from the antral follicles (3.0-6.0 $\mathrm{mm}$ in diameter) by aspiration. COCs displaying at least three layers of compacted cumulus cells were selected and cultured in NCSU23 medium [19] supplemented with $0.6 \mathrm{mM}$ cysteine, $10 \mathrm{ng} / \mathrm{ml}$ epidermal growth factor (EGF), $10 \%$ (v/v) porcine follicular fluid, $75 \mu \mathrm{g} / \mathrm{ml}$ potassium penicillin $\mathrm{G}, 50 \mu \mathrm{g} / \mathrm{ml}$ streptomycin sulfate, $10 \mathrm{IU} / \mathrm{ml}$ equine chorionic gonadotropin (eCG; Teikoku Hormone Medical, Tokyo, Japan) and $10 \mathrm{IU} / \mathrm{ml}$ human chorionic gonadotropin (hCG; Teikoku Hormone Medical). COCs were cultured for $22 \mathrm{~h}$ with eCG and hCG and then for $20 \mathrm{~h}$ without these hormones in a humidified atmosphere of $5 \% \mathrm{CO}_{2}$ and $95 \%$ air at $38.5 \mathrm{C}$ [20].

IVM oocytes with expanded cumulus cells were treated with $1 \mathrm{mg} / \mathrm{ml}$ hyaluronidase dissolved in Tyrode's lactose medium supplemented with 10 $\mathrm{mM}$ Hepes and $0.3 \%(\mathrm{w} / \mathrm{v})$ polyvinylpyrrolidone (PVP; Hepes-TL-PVP) and were denuded of cumulus cells by gentle pipetting. Oocytes showing evenly granulated ooplasm and extrusion of the first polar body were selected for experiments.

\section{Sperm preparation}

Commercially available boar semen (Duroc) suitable for artificial insemination was used to prepare sperm for ICSI. Sperm were washed twice by centrifugation at $100 \times \mathrm{g}$ for $10 \mathrm{~min}$ in Nucleus Isolation Medium [21] supplemented with $0.1 \%$ bovine serum albumin (NIM-BSA) to remove the extender. The sperm concentration was adjusted to $2.5-5 \times 10^{7} / \mathrm{ml}$ before the various pretreatments were performed. The sperm suspension was maintained at room temperature for less than $30 \mathrm{~min}$ until use.

\section{Ca-ionophore and Triton-X treatment}

To disrupt the membrane of unfrozen pig sperm, Ca-ionophore (Ca-I) A23187 (C-7522) was used to induce an acrosomal reaction or the surfactant TritonX-100 was used.

Ca-I was used to induce an acrosomal reaction as described by Nakai et al. [22]. Ca-I was added (final concentration: $10 \mu \mathrm{M}$ ) to a pig fertilization medium 
(pig-FM) that was equilibrated beforehand in an incubator [23, 24]. The sperm concentration of the resulting medium was adjusted to $2.5 \times 10^{6} / \mathrm{ml}$, and the medium was incubated for $90 \mathrm{~min}$ at $37 \mathrm{C}$. All of the above procedures were performed in the dark. To confirm induction of the acrosome reaction, sperm were then subjected to triple staining $[23,25,26]$. Following Ca-I treatment, the sperm was diluted using an equal amount of $1 \%$ trypan blue and stained for $15 \mathrm{~min}$ at $37 \mathrm{C}$. After staining, the suspension was smeared over a glass slide, and before the suspension completely dried, the excess trypan blue was removed using Beltsville thawing solution (BTS) [27]. The sperm were fixed for 15 min using 3\% glutaraldehyde and washed using distilled water. Next, the sperm were stained using $0.4 \%$ Bismarck Brown Y staining solution ( $\mathrm{pH}$ 5.3) for $5 \mathrm{~min}(40 \mathrm{C})$, washed using distilled water and again stained using $0.8 \%$ rose Bengal solution ( $\mathrm{pH}$ 5.3) for $20 \mathrm{~min}(25 \mathrm{C})$. After washing with distilled water, the acrosome reaction and sperm survival were examined under microscopy $(\times 400)$.

For treatment with surfactant, TritonX-100 was added to the sperm suspension to give a final concentration of $0.05 \%(\mathrm{v} / \mathrm{v})$ [15]. After exposing the sperm to TritonX-100 on ice for $30 \mathrm{sec}$ [15], the sperm were promptly washed twice with NIM-BSA solution.

\section{Preparation of frozen sperm}

Sperm were cryopreserved using four solutions. Beltsville F5 (BF5) [27] and Niwa and Sasaki freezing (NSF) [28] were used as freezing solutions containing cryoprotective agents. Frozen sperm were prepared using BF5 and NSF as described by Pursel and Johnson [27] and Niwa and Sasaki [23, 24, 28], respectively.

BTS [27] and NIM [21] were used as freezing solutions without cryoprotective agents. Sperm were suspended using either BTS or NIM (containing $5 \%$ BSA) at a concentration of $5 \times 10^{8} / \mathrm{ml}$ and were placed in $0.25-\mathrm{ml}$ plastic freezing straws (Fujihira Industry, Tokyo, Japan) followed by plunging into liquid nitrogen. Straws of frozen sperm were thawed by soaking the straws in a $37 \mathrm{C}$ water bath for $10 \mathrm{sec}$. The sperm recovered from the straws were washed twice in NIM-BSA solution and were used in the experiments within 90 min of thawing.

\section{Isolation of sperm heads}

Prior to ICSI, sperm tails were severed by either piezo-actuated microinjector (PMM-150FU; PrimeTech, Tsuchiura, Japan) or sonication. For tail removal by piezo pulse, sperm suspended in a $12 \%$ PVP drop were aspirated tail first into the injection needle, and the heads of individual sperm were removed using a shock generated by the piezo manipulator aimed at the midpiece of the sperm. For tail removal by sonication, an ultrasonic sonicator (Honda Electronics, Aichi, Japan) was used to apply ultrasonic vibrations $(100 \mathrm{~W}, 28 \mathrm{kHz})$ for $5-$ $30 \mathrm{sec}$ to $300 \mu \mathrm{l}$ of sperm suspension $\left(5 \times 10^{7}\right.$ sperm/ $\mathrm{ml})$ in a $0.5-\mathrm{ml}$ microcentrifugation tube. This duration of sonication was determined to decapitate approximately $70 \%$ of sperm. Sonicationtreated sperm heads were used in ICSI within 60 $\min$.

\section{DNA constructs and sperm and DNA coincubation}

The 3.0-kb Sal1-Bam H1 fragment of the plasmid pCX-EGFP $[29,30]$ containing the CMV-IE enhancer combined with the chicken $\beta$-actin promoter (CAG promoter), EGFP CDNA and rabbit $\beta$ globin poly-A signal was used to examine the efficiency of foreign gene introduction by the ICSImediated method.

Sperm that had been subjected to various pretreatments, i.e., tail removal by sonication and chemical treatments, were suspended in NIM-BSA at a concentration of $2-5 \times 10^{5}$. Then, $2.5 \mu \mathrm{l}$ of DNA solution $(10 \mathrm{ng} / \mu \mathrm{l})$ was added to $7.5 \mu \mathrm{l}$ of sperm suspension, gently mixed and coincubated at room temperature for $5 \mathrm{~min}$. The resulting sperm were stored on ice until ICSI.

\section{ICSI using pig IVM oocytes}

ICSI using pig IVM oocytes was performed as reported previously [13]. Under the conditions described below, oocytes were activated by electric stimulation, and ICSI was performed within 30 min. The oocytes were washed twice in an activation solution consisting of $0.3 \mathrm{M}$ mannitol (Nacalai Tesque, Tokyo, Japan), $50 \mu \mathrm{M} \mathrm{CaCl}_{2}, 100 \mu \mathrm{M}$ $\mathrm{MgSO}_{4}$ and $0.01 \%$ PVA. They were then lined up between two wire electrodes ( $1.0 \mathrm{~mm}$ apart) in a fusion chamber overlaid with $0.2 \mathrm{ml}$ of activation solution. A single DC pulse of $150 \mathrm{~V} / \mathrm{mm}$ was applied for $100 \mu$ sec using an electric pulsing machine (ET-1; Fujihira Industry).

Approximately $1 \mu \mathrm{l}$ of sperm suspension that had been co-incubated with DNA was transferred to a $4-\mu l$ drop of $12 \%$ PVP (in D-PBS). ICSI was per- 
formed in a 4- $\mu$ l drop of Hepes-TL-PVP with 10\% fetal calf serum (FCS; JRH Bio-sciences, Lenexa, KS, USA) under mineral oil using a TE-300 inverted microscope (Nikon, Tokyo, Japan). Isolated sperm heads were aspirated from the PVP sperm drop using an injection pipette and were moved to the drop containing the oocytes. An oocyte was captured by a holding pipette, and while immobilizing the oocyte with the polar body at either the 6 or 12 o'clock position, a sperm head was injected using a piezo-actuated microinjection unit and micromanipulators.

\section{In vitro culture of embryos and observation of GFP expression}

In vitro culture of embryos was performed in 20$\mu$ droplets of modified NCSU23 supplemented with $4 \mathrm{mg} / \mathrm{ml} \mathrm{BSA}$ and $0.5 \mathrm{mg} / \mathrm{ml}$ hyaluronic acid [31] under paraffin oil in a plastic Petri dish maintained in a humidified atmosphere of $5 \% \mathrm{CO}_{2}, 5 \%$ $\mathrm{O}_{2}$ and $90 \% \mathrm{~N}_{2}$ at $38.5 \mathrm{C}$. The medium was modified by the addition of $0.17 \mathrm{mM}$ sodium pyruvate and $2.73 \mathrm{mM}$ sodium lactate instead of D-glucose for the first $48 \mathrm{~h}$ of culture [32]. The osmolality of the medium was adjusted to $290 \mathrm{mOsm}$ for the first $48 \mathrm{~h}$ and to $256 \mathrm{mOsm}$ for the rest of the culture period [33]. To culture embryos beyond the morula stage, $10 \%(\mathrm{v} / \mathrm{v})$ FCS was added to the medium. Expression of the EGFP gene in sperm-injected embryos was detected 6 days after ICSI using a Nikon inverted microscope under long-wavelength (488 nm) ultraviolet (UV) light.

Oocytes at $8 \mathrm{~h}$ after ICSI and blastocysts that developed from ICSI oocytes after culture for 7 days were fixed with aceto-alcohol (1:3). These oocytes and embryos were stained with $1 \%$ acetoorcein to enable confirmation of pronucleus formation and counting of cell numbers.

\section{Transfer of ICSI embryos}

Crossbred (Large White/Landrace $\times$ Duroc) prepubertal gilts weighing 100-105 kg were used as the recipients of ICSI embryos. To induce estrus in the gilts, 1,000 IU of eCG (Teikoku Hormone Medical) was injected intramuscularly followed by injection of 1,500 IU hCG (Teikoku Hormone Medical) $72 \mathrm{~h}$ later.

The sperm-injected oocytes were cultured for 1 or 2 days. Embryos that were morphologically normal at the 1-cell (Day 1) or 2-8-cell (Day 2) stage were selected for transfer. Embryos were trans- ferred into the oviducts of the recipient gilts approximately $48 \mathrm{~h}$ after hCG injection. At 30 days after transfer, pregnancy status was confirmed by ultrasonography, and the pregnant recipients were autopsied to recover the fetuses 32-35 days after transfer.

\section{Southern blot hybridization analysis}

Genomic DNA was extracted from whole fetal bodies using the phenol-chloroform method. EGFP probes containing the entire coding sequence were prepared by NcoI/NotI digestion from pCX-EGFP. The probes were purified by agarose gel electrophoresis and gel extraction using a QIAquick Gel Extraction Kit (Qiagen, Hilden, Germany).

To determine the copy number of transgenes integrated into transgenic pig fetus genomes, $5 \mu \mathrm{g}$ of purified genomic DNA from the transgenic fetuses and the pCX-EGFP fragment, which was diluted to make a series of copy-number controls (1-100 copies per genome), were digested using $\mathrm{NcoI} / \mathrm{NotI}$ and probed with [ $\left.{ }^{32} \mathrm{P}\right]$-labeled EGFP probes. The transgene copy number was determined by comparison with the copy-number controls.

Experiment I: Effects of sperm pretreatments on postICSI embryogenesis and EGFP expression efficiency

With ICSI-mediated gene transfer, damage to the sperm plasma membrane is believed to be the main element affecting the efficiency of DNA introduction by sperm into oocytes. Hence, in the present study using sperm treated under eight sets of conditions, the EGFP gene was transferred into pig IVM oocytes by the ICSI-mediated method, and then the normal fertilization rate, in vitro embryo development rate and transgene expression efficiency were compared. The treatment conditions were as follows. Treatment 1 utilized unfrozen sperm heads removed by piezo pulse. Treatment 2 utilized unfrozen sperm heads removed by sonication. Treatment 3 utilized Triton-X-treated sperm heads removed by sonication. Treatment 4 utilized Ca-I-treated sperm heads removed by sonication. Treatments 5 and 6 utilized the heads of sperm frozen using a freezing solution containing a cryoprotective agent (BF5 or NSF) and removed by sonication. Treatments 7 and 8 utilized the heads of sperm frozen using a freezing solution that did not contain a cryoprotective agent (NIM and BTS) and removed by sonication. 
ICSI-MEDIATED TRANSGENESIS IN PIGS

Table 1. In vitro development and EGFP expression of pig embryos fertilized by ICSI following various sperm treatments

\begin{tabular}{|c|c|c|c|c|c|c|}
\hline \multicolumn{3}{|c|}{ Sperm treatment } & \multicolumn{3}{|c|}{ Embryonic development } & GFP expression \\
\hline $\begin{array}{c}\text { Experimental } \\
\text { treatment }\end{array}$ & $\begin{array}{l}\text { Freeze- } \\
\text { thawing }\end{array}$ & $\begin{array}{l}\text { Membrane disruption } \\
\text { and tail removal }\end{array}$ & $\begin{array}{l}2 \mathrm{PN} \text { formation } \\
\quad \text { rate }(\%)\end{array}$ & $\begin{array}{c}\text { Blastocysts/cultured } \\
\text { embryos (\%) }\end{array}$ & $\begin{array}{l}\text { Cell numbers in blastocysts } \\
\text { (mean } \pm \text { SEM) }\end{array}$ & $\begin{array}{c}\text { Positive/ } \\
\text { blastocysts (\%) }\end{array}$ \\
\hline 1 & Unfrozen & $\begin{array}{l}\text { Decapitation } \\
\text { by Piezo pulse }\end{array}$ & $\begin{array}{l}9 / 30^{a} \\
(30.0)\end{array}$ & $17 / 120(14.2)^{\mathrm{a}}$ & $38.7 \pm 5.0^{\mathrm{abc}}$ & $\begin{array}{l}2 / 17 \\
(11.8)^{\mathrm{c}}\end{array}$ \\
\hline 2 & Unfrozen & Sonication & $\begin{array}{c}19 / 27^{\mathrm{bcd}} \\
(70.4)\end{array}$ & $21 / 117(17.9)^{a b}$ & $25.0 \pm 4.5^{\mathrm{a}}$ & $\begin{array}{l}11 / 21 \\
(52.4)^{\mathrm{b}}\end{array}$ \\
\hline 3 & Unfrozen & $\begin{aligned} & \text { Triton- } X \\
+ & \text { sonication }\end{aligned}$ & $\begin{array}{c}22 / 35^{\mathrm{bc}} \\
(62.9)\end{array}$ & $25 / 93(26.9)^{b c}$ & $29.0 \pm 3.8^{\mathrm{ab}}$ & $\begin{array}{c}5 / 25 \\
(20.0)^{\mathrm{ac}}\end{array}$ \\
\hline 4 & Unfrozen & $\begin{array}{l}\text { Ca-ionophore } \\
+ \text { sonication }\end{array}$ & $\begin{array}{c}14 / 30 \text { ab } \\
(46.7)\end{array}$ & $24 / 116(20.7)^{a b}$ & $38.4 \pm 4.7^{b c}$ & $\begin{array}{c}10 / 24 \\
(41.7)^{\mathrm{ab}}\end{array}$ \\
\hline 5 & $\begin{array}{l}\text { Frozen in BF5 } \\
\text { (with CPA) }\end{array}$ & Sonication & $\begin{array}{c}15 / 25^{\mathrm{bc}} \\
(60.0)\end{array}$ & $21 / 73(28.8)^{b c}$ & $29.1 \pm 2.8^{a b}$ & $\begin{array}{l}13 / 21 \\
(61.9)^{\mathrm{b}}\end{array}$ \\
\hline 6 & $\begin{array}{l}\text { Frozen in NSF } \\
\text { (with CPA) }\end{array}$ & Sonication & $\begin{array}{l}14 / 21 \mathrm{bcd} \\
(66.7)\end{array}$ & $26 / 77(33.8)^{c}$ & $45.5 \pm 5.2^{\mathrm{c}}$ & $\begin{array}{l}12 / 26 \\
(46.2)^{b}\end{array}$ \\
\hline 7 & $\begin{array}{l}\text { Frozen in NIM } \\
\text { (no CPA) }\end{array}$ & Sonication & $\begin{array}{c}18 / 22^{\mathrm{cd}} \\
(81.8)\end{array}$ & $14 / 61(23.0)^{a b c}$ & $32.1 \pm 5.7^{\mathrm{ac}}$ & $\begin{array}{c}6 / 14 \\
(42.9)^{a b}\end{array}$ \\
\hline 8 & $\begin{array}{l}\text { Frozen in BTS } \\
\quad \text { (no CPA) }\end{array}$ & Sonication & $\begin{array}{c}20 / 23^{\mathrm{d}} \\
(87.0)\end{array}$ & $15 / 62(24.2) \mathrm{abc}$ & $27.0 \pm 4.6^{\mathrm{ab}}$ & $\begin{array}{l}10 / 15 \\
(66.7)^{\mathrm{b}}\end{array}$ \\
\hline
\end{tabular}

$\mathrm{a}, \mathrm{b}, \mathrm{c}, \mathrm{d}$ Values with different superscripts within the same column differ significantly $(\mathrm{P}<0.05)$.

Experiment II: Efficiency of transgenic fetus production by ICSI-mediated gene transfer using frozen-thawed sperm

Using sperm heads prepared by sonication from sperm that were frozen and thawed using BTS, embryos were produced by ICSI-mediated gene transfer and were transferred to pigs to investigate embryogenesis and gene transfer efficiency. Fetuses were recovered 32-35 days after transfer, and Southern blotting using an EGFP gene fragment as a probe was used to determine the presence of the transgene in the fetuses.

\section{Statistical analysis}

At least three replicate trials were conducted for each experiment. For proportional data, differences between groups were detected by one-way analysis of variance. When differences were found in the rate of embryonic development and EGFP expression in vitro, $\chi^{2}$ analysis was used to calculate the $\mathrm{P}$ value. For blastocyst cell numbers, differences between groups were determined using the Student's $t$-test. The level of significance was set at $\mathrm{P}<0.05$.

\section{Results}

Experiment I: Effects of sperm pretreatments on postICSI embryogenesis and EGFP expression efficiency

Table 1 summarizes the pronuclear formation, in vitro development and EGFP expression of the embryos produced by ICSI-mediated gene transfer. Using sperm subjected to various pretreatments, the EGFP gene was transferred into pig IVM oocytes.

When ICSI was performed using unfrozen sperm heads removed by piezo-pulse, the pronuclear formation and blastocyst formation rates were both low, $30.0 \%(9 / 30)$ and $14.2 \%(17 / 120)$, respectively (Fig. 1). The EGFP expression rate of the resulting blastocysts was $11.8 \%(2 / 17)$. With unfrozen sperm heads removed by sonication, pronuclear formation $(19 / 27,70.4 \%)$ and EGFP expression efficiency $(11 / 21,52.4 \%)$ improved significantly $(\mathrm{P}<0.05)$. However, the blastocyst formation rate did not improve and remained at $17.9 \%(21 / 117)$.

The rate of acrosome reaction induction for the Ca-I treatment was $81.7 \%$, and sperm survival was $48.6 \%$. Use of the heads of chemically treated sperm (Ca-I or TritonX-100) did not markedly improve the rates of pronucleus formation, blastocyst formation or EGFP expression.

When ICSI was performed using frozen-thawed sperm heads, the pronuclear and blastocyst formation rates tended to be generally high (60.0-87.0 

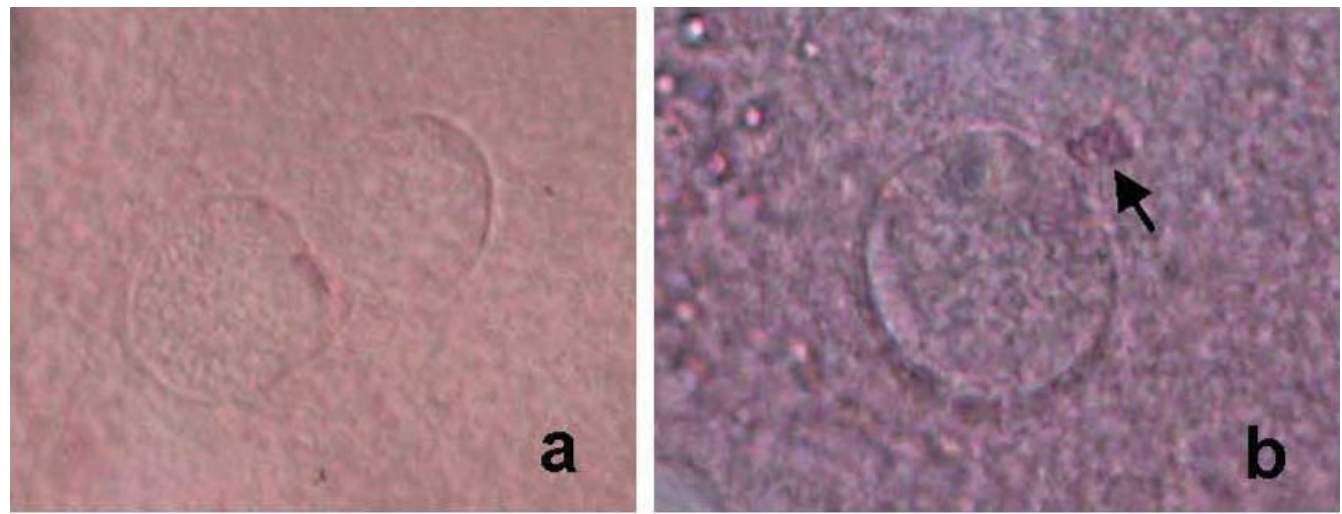

Fig. 1. Morphological changes in injected sperm heads following ICSI-mediated gene transfer. a) Formation of two pronuclei and $\mathrm{b}$ ) absence of sperm head decondensation were observed $8 \mathrm{~h}$ after injection into IVM oocytes $(\times 400)$.
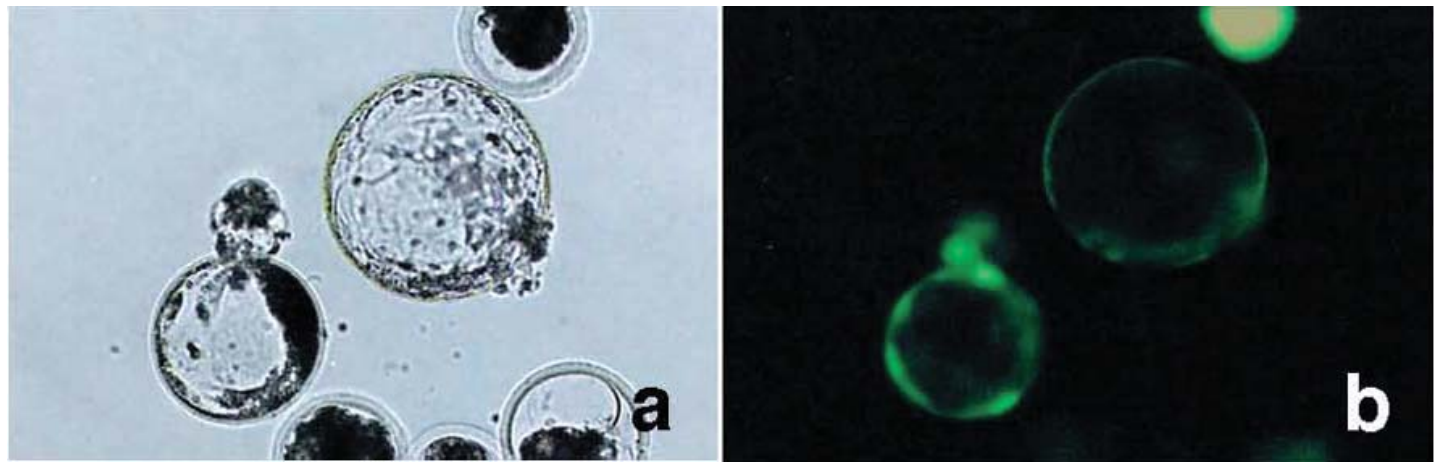

Fig. 2. Development and EGFP expression of blastocysts obtained by ICSI-mediated gene transfer. Day-6 blastocysts obtained by ICSI using frozen sperm heads coincubated with EGFP DNA (a) and the EGFP expression of these blastocysts $(b)(\times 200)$.

and $23.0-33.8 \%$, respectively). Furthermore, EGFP expression was confirmed in $42.9(6 / 14)$ to $66.7 \%$ $(10 / 15)$ of blastocysts. The EGFP expression of the BTS frozen group was particularly high at $66.7 \%$ (Fig. 2).

Experiment II: Efficiency of transgenic fetus production by ICSI-mediated gene transfer using frozen-thawed sperm

The efficiency of transgene introduction by ICSImediated gene transfer was verified using transgenic fetuses. The heads of sperm frozen using BTS were removed by sonication. A total of 219 ICSI oocytes were transferred into two recipients, and both recipients became pregnant. At 32-35 days of gestation, the recipients were dissected, and a total of seven fetuses were recovered. When these fetuses were analyzed under a portable UV light, two fetuses fluoresced. DNA samples extracted from EGFP-positive fetuses were subjected to Southern blotting, and integration of approximately 10 and 30 copies of the gene was confirmed (Fig. 3).

\section{Discussion}

In pig ICSI-mediated gene transfer, which sperm pretreatments are beneficial for post-ICSI embryogenesis and gene transfer efficiency has not previously been fully clarified. The present study thus identified several important factors for successful ICSI-mediated gene transfer.

When injecting sperm into an oocyte, the solvent 

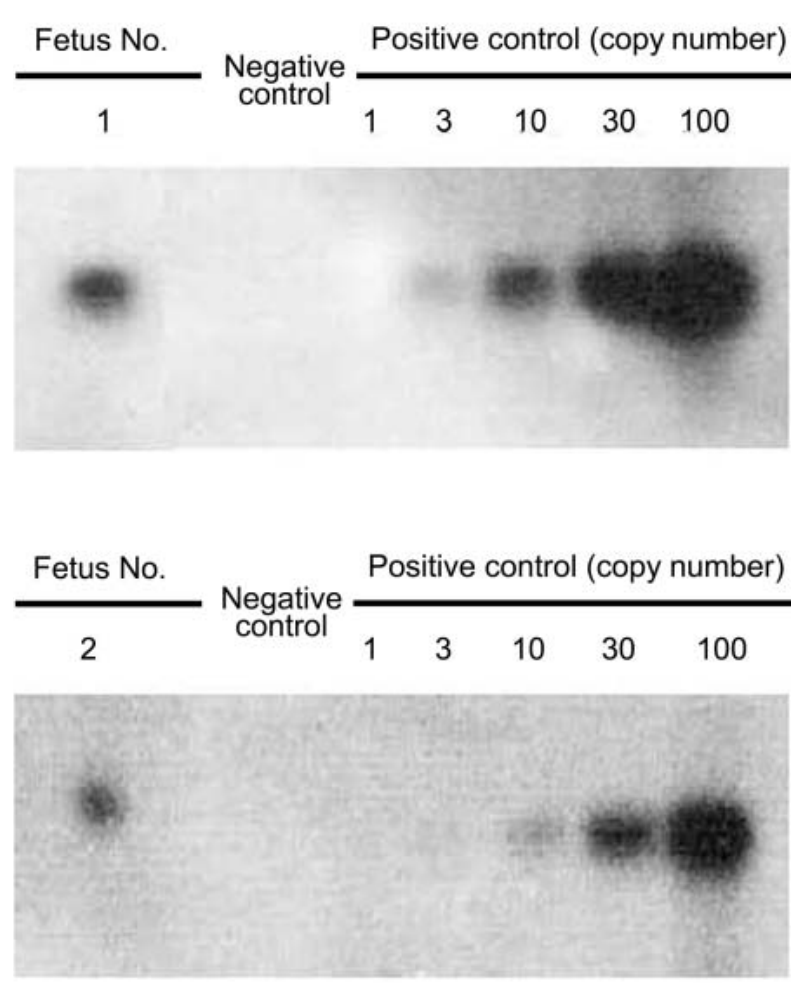

Fig. 3. Transgene copy numbers of fetuses obtained by ICSImediated gene transfer.

in which the sperm is suspended also enters the ooplasm. This solvent prevents intermingling of the ooplasm and intracellular components of the sperm and negatively affects subsequent embryogenesis [34]. For these reasons, when injecting sperm, the amount of solvent entering the ooplasm should be minimized; at the same time, to simplify the entire sperm injection procedure, studies have also documented the advantages of using only sperm heads in pig ICSI [13, 22, 35].

Separation of the sperm head from the sperm tail by applying a pulse generated by a piezo manipulator is often used in mouse ICSI [36]. However, in the present study, when using unfrozen sperm heads removed by piezo pulse, the fertility rate was significantly lower than with the other sperm pretreatments. Even $8 \mathrm{~h}$ after ICSI, condensed or swollen sperm heads were observed in $70 \%$ of the oocytes (Fig. 1). The reason for this might have been that since the degree of damage to the sperm plasma membrane for ICSI using unfrozen sperm heads (tail removal by piezo pulse) was milder compared with that for the other sperm pretreatment groups, a longer period of time was required for ooplasm factors to reach the sperm nucleus, subsequently delaying nuclear swelling. The gene transfer rate was also low when removing sperm heads by piezo pulse. The piezo pulse is thought to damage the sperm plasma membrane to some extent $[37,38]$, but this does not make the sperm plasma membrane suitable for ICSI-mediated gene transfer. The above results suggest that removing the heads of unfrozen sperm by piezo pulse is ineffective as a sperm pretreatment for ICSI-mediated gene transfer.

Conversely, use of sperm heads removed by sonication improved DNA transfer efficacy. This indicates that sonication-induced sperm plasma membrane damage is beneficial for ICSI-mediated gene transfer. Sonication may damage sperm DNA [39], but the present results suggest that in pig sperm, sonication does not have any significant negative impact on embryogenesis.

Previous studies have reported that the acrosome reaction for sperm used for ICSI does not affect embryogenesis [22]. In addition, in the present study, even when sperm were chemically treated using Ca-I or Triton-X before sonication, embryogenesis and DNA integration efficiency did not improve. The rate of acrosome reaction induction for the Ca-I treatment conditions that we employed was confirmed to be $\geq 80 \%$. The data collected from our preliminary experiment showed that the rate of acrosome reaction induction for Triton-X-treated sperm was high at $95.3 \%$ and was the same as for Ca-I-treated sperm, and this was markedly higher than that for sonication-treated sperm $(11.3 \%)$. Acrosome reaction-induced changes in the sperm plasma membrane were thus unlikely to be advantageous to embryogenesis or DNA transfer efficiency.

Conversely, the results of the present study showed that the heads of frozen-thawed sperm obtained by sonication could function as DNA vectors in ICSI-mediated gene transfer, irrespective of whether a cryoprotective agent was used during sperm cryopreservation. The pig sperm plasma membrane, and the acrosomal membrane in particular, is likely damaged by freezing and thawing, and the plasma membranes of sperm that are frozen without a cryoprotective agent are thought to be markedly damaged. Transgene integration is known to be influenced by the degree of damage to the sperm cell membrane [15], and this explains the high EGFP expression rates for embryos fertilized 
using cryopreserved sperm frozen without a cryoprotective agent (BTS). On the other hand, excessive plasma membrane damage has been suggested to induce DNA damage and may lower the quality of ICSI embryos [40, 41]. Therefore, further investigations are needed to clarify the conditions required to ensure both uptake of transgene by sperm with a damaged cell membrane and sperm DNA integrity at the same time.

Although several groups have reported production of piglets by ICSI, efficiency has been low [13, 22, 42-47]. One cause is insufficient and delayed decondensation of injected sperm nuclei and subsequent failure of male pronuclear formation [48-50]. Protamine is a nuclear protein in the sperm nucleus, and disulfide bonds make this protein morphologically and chemically stable, but stability varies between species [51,52]. For example, the disulfide bonds of bovine sperm are known to be stronger than those of human or mouse sperm [52]. In pigs, sperm nucleus decondensation failure or delay can occur following ICSI, and the disulfide bonds in pig sperm protamine resemble those of bovine protamine. Dithiothreital (DTT) induces nuclear decondensation by severing the disulfide bonds of sperm nuclear protamine, but DTT reportedly does not work effectively in pig sperm $[53,54]$. Numerous points thus remain uncertain with regard to the factors affecting swelling of pig sperm heads after ICSI, but sperm heads with damaged plasma membranes are more likely to undergo swelling inside the ooplasm, and this is thought to assist fertilization and embryogenesis [38, 46, 55]. While considering these characteristics of pig sperm, further investigations into the conditions of ICSI are necessary.

In the present study, use of unfrozen sperm was not found to be beneficial to fertilization, embryogenesis or gene transfer efficiency in pig ICSImediated gene transfer. While further investigations are warranted, combining frozen-thawed sperm with tail removal by sonication appears to be effective in facilitating ICSI-mediated gene transfer.

\section{Acknowledgments}

We would like to thank Prof. M. Okabe for generously providing us with pCX-EGFP. We are also grateful to K. Kameda, K. Nakata and H. Kawano for their invaluable technical assistance. This work was supported in part by the $21^{\text {st }}$ Century Green Frontier Research Project of the National Institute of Agrobiological Science (Japan), the Program for Promotion of Basic Research Activities for Innovative Biosciences (PROBRAIN) and a "Biotechnology Venture Research-and-Development Base Maintenance Enterprise" Project for Private Universities subsidy from the Ministry of Education, Culture, Sports, Science and Technology of Japan (2002-2006).

\section{References}

1. Niemann H. Current status and perspectives for the generation of transgenic pigs for xenotransplantation. Ann Transplant 2001; 6: 6-9.

2. Piedrahita J, Mir B. Cloning and transgenesis in mammals: implications for xenotransplantation. Am J Transplant 2004; 4: 43-50.

3. Cox A, Zhong R. Current advances in xenotransplantation. Hepatobiliary Pancreat Dis Int 2005; 4: 490-494.

4. Petters R, Alexander C, Wells K, Collins E, Sommer J, Blanton M, Rojas G, Hao Y, Flowers W, Banin E, Cideciyan A, Jacobson S, Wong F. Genetically engineered large animal model for studying cone photoreceptor survival and degeneration in retinitis pigmentosa. Nat Biotechnol 1997; 15: 965970.

5. Hao Y, Yong H, Murphy C, Wax D, Samuel M, Rieke A, Lai L, Liu Z, Durtschi D, Welbern V, Price
E, McAllister R, Turk J, Laughlin M, Prather R, Rucker E. Production of endothelial nitric oxide synthase (eNOS) over-expressing piglets. Transgenic Res 2006; 15: 739-750.

6. Velander W, Johnson J, Page R, Russell C, Subramanian A, Wilkins T, Gwazdauskas F, Pittius C, Drohan W. High-level expression of a heterologous protein in the milk of transgenic swine using the cDNA encoding human protein C. Proc Natl Acad Sci USA 1992; 15: 12003-12007.

7. Saeki K, Matsumoto K, Kinoshita M, Suzuki I, Tasaka Y, Kano K, Taguchi Y, Mikami K, Hirabayashi M, Kashiwazaki N, Hosoi Y, Murata N, Iritani A. Functional expression of a Delta12 fatty acid desaturase gene from spinach in transgenic pigs. Proc Natl Acad Sci USA 2004; 27: 6361-6366.

8. Machaty Z, Bondioli K, Ramsoondar J, Fodor W. The use of nuclear transfer to produce transgenic 
pigs. Cloning Stem Cells 2002; 4: 21-27.

9. Lai L, Prather R. Creating genetically modified pigs by using nuclear transfer. Reprod Biol Endocrinol 2003; 7: 82.

10. Prather R, Hawley R, Carter D, Lai L, Greenstein J. Transgenic swine for biomedicine and agriculture. Theriogenology 2003; 59: 115-123.

11. Niemann $\mathbf{H}$, Kues W, Carnwath J. Transgenic farm animals: present and future. Rev Sci Tech 2005; 24: 285-298.

12. Chang K, Qian J, Jiang M, Liu YH, Wu MC, Chen CD, Lai CK, Lo HL, Hsiao CT, Brown L, Bolen JJ, Huang HI, Ho PY, Shih PY, Yao CW, Lin WJ, Chen CH, Wu FY, Lin YJ, Xu J, Wang K. Effective generation of transgenic pigs and mice by linker based sperm-mediated gene transfer. BMC Biotechnology 2002; 19: 5.

13. Kurome M, Ueda H, Tomii R, Naruse K, Nagashima $\mathbf{H}$. Production of transgenic-clone pigs by the combination of ICSI-mediated gene transfer with somatic cell nuclear transfer. Transgenic Res 2006; 15 : 229-240.

14. Lavitrano M, Busnelli M, Cerrito M, Giovannoni R, Manzini S, Vargiolu A. Sperm-mediated gene transfer. Reprod Fertil Dev 2006; 18: 19-23.

15. Perry ACF, Wakayama T, Kishikawa H, Kasai T, Okabe M, Toyoda Y, Yanagimachi R. Mammalian transgenesis by intracytoplasmic sperm injection. Science 1999; 284: 1180-1183.

16. Moreira P, Giraldo P, Cozar P, Pozueta J, Jimenez A, Montoliu L, Gutierrez-Adan A. Efficient generation of transgenic mice with intact yeast artificial chromosomes by intracytoplasmic sperm injection. Biol Reprod 2004; 71: 1943-1947.

17. Suganuma R, Pelczar P, Spetz J, Hohn B, Yanagimachi R, Moisyadi S. Tn5 transposase-mediated mouse transgenesis. Biol Reprod 2005; 73: 1157-1163.

18. Hirabayashi M, Kato M, Ishikawa A, Kaneko R, Yagi T, Hochi S. Factors affecting production of transgenic rats by ICSI-mediated DNA transfer: effects of sonication and freeze-thawing of spermatozoa, rat strains for sperm and oocyte donors, and different constructs of exogenous DNA. Mol Reprod Dev 2005; 70: 422-428.

19. Petters RM, Wells KD. Culture of pig embryos. J Reprod Fert 1993; 48 (Suppl): 61-73.

20. Funahashi H, Day B. Effects of the duration of exposure to hormone supplements on cytoplasmic maturation of pig oocytes in vitro. J Reprod Fertil 1993; 98: 179-185.

21. Kuretake S, Kimura Y, Hoshi K, Yanagimachi R. Fertilization and development of mouse oocytes injected with isolated sperm heads. Biol Reprod 1996; 55: 789-795.

22. Nakai M, Kashiwazaski N, Takizawa A, Hayashi Y, Nakatsukasa E, Fuchimoto D, Noguchi J, Kaneko H, Shino M, Kikuchi K. Viable piglets gen- erated from porcine oocytes matured in vitro and fertilized by intracytoplasmic sperm head injection. Biol Reprod 2003; 68: 1003-1008.

23. Kikuchi $K$, Nagai T, Kashiwazaki N, Ikeda $\mathbf{H}$, Noguchi J, Shimada A, Soloy E, Kaneko H. Cryopreservation and ensuing in vitro fertilization ability of boar spermatozoa from epididymides stored at 4 degrees C. Theriogenology 1998; 50: 615-623.

24. Suzuki K, Asano A, Eriksson B, Niwa K, Nagai T, Rodriguez-Martinez $\mathbf{H}$. Capacitation status and in vitro fertility of boar spermatozoa: effects of seminal plasma, cumulus-oocyte-complexes-conditioned medium and hyaluronan. Int J Androl 2002; 25: 8493.

25. Ikeda H, Kikuchi K, Noguchi J, Takeda H, Shimada A, Mizokami T, Kaneko H. Effect of preincubation of cryopreserved porcine epididymal sperm. Theriogenology 2002; 57: 1309-1318.

26. Talbot T, Chacon R. A triple-stain technique for evaluating normal acrosome reactions of human sperm. J Exp Zool 1981; 215: 201-208.

27. Pursel VG, Johnson LA. Freezing of boar spermatozoa: Freezing capacity with concentrated semen and a new thawing procedure. J Anim Sci 1975; 40: 99102.

28. Niwa T. Preparation of extenders. In: Niwa T (eds.), Manual for Cryopreservation of Pig Spermatozoa. Tokyo: Japanese Artificial Insemination Association; 1989: 19-23.

29. Ikawa M, Kominami K, Yoshimura Y, Tanaka K, Nishimune $\mathbf{Y}$, Okabe $\mathbf{M}$. A rapid and non-invasive selection of transgenic embryos before implantation using green fluorescent protein (GFP). FEBS Let 1995; 375: 125-128.

30. Okabe M, Ikawa M, Kominami K, Nakanishi T, Nishimune Y. 'Green mice' as a source of ubiquitous green cells. FEBS Let 1997; 407: 313-319.

31. Miyano T, Hiro-oka RE, Kano K, Miyake M, Kusunoki H, Kato S. Effects of hyaluronic acid on the development of 1- and 2-cell porcine embryos to the blastocyst stage in vitro. Theriogenology 1994; 41: 1299-1305.

32. Kikuchi K, Onishi A, Kashiwazaki N, Iwamoto M, Noguchi J, Kaneko H, Akita T, Nagai T. Successful piglet production after transfer of blastocysts produced by a modified in vitro system. Biol Reprod 2002; 66: 1033-1041.

33. Nguyen V, Kure-bayashi $S$, Harayama $H$, Nagai $T$, Miyake M. Stage-specific effects of the osmolarity of a culture medium on the development of parthenogenetic diploids in the pig. Theriogenology 2003; 59: 719-734.

34. Palermo G, Schlegel P, Colombero L, Zaninovic N, Moy F, Rosenwaks Z. Aggressive sperm immobilization prior to intracytoplasmic sperm injection with immature spermatozoa improves fertilization and pregnancy rates. Hum Reprod 1996; 11: 1023- 
1029.

35. Kim NH, Lee JW, Jun SH, Lee HT, Chung KS. Fertilization of porcine oocytes following intracytoplasmic spermatozoon or isolated sperm head injection. Mol Reprod Dev 1998; 51: 436-444.

36. Wakayama T, Whittingham $D$, Yanagimachi $R$. Production of normal offspring from mouse oocytes injected with spermatozoa cryopreserved with or without cryoprotection. J Reprod Fertil 1998; 112: 1117.

37. Yanagida $\mathbf{K}$, Katayose $\mathbf{H}$, Hirata $\mathbf{S}$, Yazawa $\mathbf{H}$, Hayashi S, Sato A. Influence of sperm immobilization on onset of $\mathrm{Ca}(2+)$ oscillations after ICSI. Hum Reprod 2001; 16: 148-152.

38. Katayama M, Sutovsky P, Yang B, Cantley T, Rieke A, Farwell R, Oko R, Day BN. Increased disruption of sperm plasma membrane at sperm immobilization promotes dissociation of perinuclear theca from sperm chromatin after intracytoplasmic sperm injection in pigs. Reproduction 2005; 130: 907-916.

39. Martin R, Ko E, Rademaker A. Human sperm chromosome complements after microinjection of hamster eggs. J Reprod Fertil 1988; 84: 179-186.

40. Rybouchkin AV, De Sutter P, Dhont M. Unprotected freezing of human spermatozoa exerts a detrimental effect on their oocyte activating capacity and chromosome integrity. Zygote 1996; 4: 263-268.

41. Szczygiel M, Moisyadi S, Ward W. Expression of foreign DNA is associated with paternal chromosome degradation in intracytoplasmic sperm injection-mediated transgenesis in the mouse. Biol Reprod 2003; 68: 1903-1910.

42. Kolbe T, Holtz W. Birth of a piglets derived from an oocytes fertilized by intracytoplasmic sperm injection (ICSI). Anim Reprod Sci 2000; 64: 97-101.

43. Martin MJ. Development of in vivo-matured porcine oocytes following intracytoplasmic sperm injection. Biol Reprod 2000; 63: 109-112.

44. Lai L, Sun Q-Y, Wu G, Murphy CN, Kühholzer B, Park K-W, Bonk AJ, Day BN, Prather RS. Development of porcine embryos and offspring after intracytoplasmic sperm injection with liposome transfected or non-transfected sperm into in vitro matured oocytes. Zygote 2001; 9: 339-346.

45. Probst S, Rath D. Production of piglets using intracytoplasmic sperm injection (ICSI) with flowcytometrically sorted boar semen and artificially activated oocytes. Theriogenology 2003; 59: 961-973.

46. Yong H, Hao Y, Lai L, Li R, Murphy C, Rieke A,
Wax D, Samuel M, Prather R. Production of a transgenic piglet by a sperm injection technique in which no chemical or physical treatments were used for oocytes or sperm. Mol Reprod Dev 2006; 73: 595-599.

47. Katayama M, Rieke A, Cantley T, Murphy C, Dowell L, Sutovsky P, Day B. Improved fertilization and embryo development resulting in birth of live piglets after intracytoplasmic sperm injection and in vitro culture in a cysteine-supplemented medium. Theriogenology 2007; 67: 835-847.

48. Kren R, Kikuchi K, Nakai M, Miyano T, Ogushi S, Nagai T, Suzuki S, Fulka J, Fulka JJ. Intracytoplasmic sperm injection in the pig: where is the problem. J Reprod Dev 2003; 49: 271-273.

49. Lee J, Tian X, Yang X. Failure of male pronucleus formation is the major cause of lack of fertilization and embryo development in pig oocytes subjected to intracytoplasmic sperm injection. Biol Reprod 2003; 68: 1341-1347.

50. Katayama M, Miyano T, Miyake $\mathbf{M}$, Kato $\mathbf{S}$. Progesterone treatment of boar spermatozoa improves male pronuclear formation after intracytoplasmic sperm injection into porcine oocytes. Zygote 2002; 10: 95-104.

51. Calvin H. Comparative analysis of the nuclear basic proteins in rat, human, guinea pig, mouse and rabbit spermatozoa. Biochim Biophys Acta 1976; 15: 377389.

52. Perreault S, Barbee R, Elstein $K$, Zucker R, Keefer C. Interspecies differences in the stability of mammalian sperm nuclei assessed in vivo by sperm microinjection and in vitro by flow cytometry. Biol Reprod 1988; 39: 157-167.

53. Yong $\mathbf{H}$, Hong J, Kang $\mathbf{S}$, Lee B, Lee E, Hwang W. Sperm movement in the ooplasm, dithiothreitol pretreatment and sperm freezing are not required for the development of porcine embryos derived from injection of head membrane-damaged sperm. Theriogenology 2005; 63: 783-794.

54. Nakai M, Kashiwazaki N, Takizawa A, Maedomari N, Ozawa M, Noguchi J, Kaneko H, Shino M, Kikuchi K. Morphologic changes in boar sperm nuclei with reduced disulfide bonds in electrostimulated porcine oocytes. Reproduction 2006; 131: 603611.

55. Lee J, Yang X. Factors affecting fertilization of porcine oocytes following intracytoplasmic injection of sperm. Mol Reprod Dev 2004; 68: 96-102. 